\title{
Meteodiversity: a new concept for quantifying meteorological diversity
}

\author{
Jordi Mazon ${ }^{1,2}$ and \\ David Pino ${ }^{1,3}$ \\ ${ }^{1}$ Department of Physics, Universitat \\ Politècnica de Catalunya, \\ BarcelonaTech, Catalonia, Spain \\ 2UNESCO chair in Sustainability, \\ Universitat Politècnica de Catalunya, \\ BarcelonaTech, Catalonia, Spain \\ ${ }^{3}$ Institute of Space Studies of Catalonia \\ (IEEC-UPC), Catalonia, Spain
}

\section{Introduction}

Biologists and ecologists use the term biodiversity to describe the variety of organisms existing in different ecosystems. More specifically, biodiversity contemplates variations in genetics, ecosystems and species within a defined area such as a forest, a desert or a marine area, among other examples.

Several authors have proposed different ways of quantifying biodiversity in order to evaluate trends in different ecosystems. One of the more common parameters used in ecology is the Shannon index, which is usually symbolised by $H$ (Shannon, 1948). It measures the entropy (uncertainty) in predicting the species identity of an individual taken at random from the dataset of interest. The proposed index is calculated as follows:

$$
H=-\sum_{i=1}^{R} p_{i} \ln p_{i}
$$

where $p_{i}$ is the proportion of individuals belonging to species $i$ within a dataset of interest, and $R$ is the total number of different species. This index increases with the abundance of species, and it is zero if only one species is in the database of interest. Despite there being no theoretical upper limit, this index takes values between 0.5 and 5 in the majority of natural ecosystems and is usually between 1 and 3 in the main ecosystems. Values lower than 1 are associated with poor biodiversity (typically in deserts), while values higher than 3 are related to greater biodiversity (e.g. rainforest). The biodiversity index is a useful parameter for quantifying and studying the biodiversity of an ecosystem. This param- eter allows investigation of the variations over time of types of life, particularly those arising from environmental changes.

Currently, meteorologists and climatologists have no comparable index for quantifying the diversity of meteorological phenomena in an area over a certain period of time.

One of the most popular climatic classifications was developed by Köppen and Geiger (1936) and modified later by other authors (e.g. Peel et al., 2007). The Köppen classification is based firstly on five vegetation groups that indicate the zones in which the plants live (equatorial - $A$, arid - $B$, warm temperate - $C$, snow zone - D and polar areas $-E$ ), then secondly on the annual cycles of precipitation and temperature. The criteria developed by Köppen for the climatic classification has been used by several authors with different purposes: to study climatic variation (e.g. Fraedrich et al., 2001; Gonzalez, 2001; Grieser et al., 2006); to evaluate the influence of climate change (e.g. Wang and Overland, 2004); to validate Global Circulation Models and to analyse scenario runs on spatio-temporal variations of climate (Guetter et al., 1990; Lohmann et al., 1993); to compare with observational datasets (Kalvova et al., 2003); and to assess the sensitivity of climate types to long-term climate change (Triantafyllou and Tsonis, 1994), among other studies.

However, it is important to remark that the Köppen classification is based only on average values of air temperature and precipitation. Although climatologists and meteorologists analysing historical weather are able to reconstruct weather conditions of the past (Pino et al., 2016), often they limit their analysis of weather diversity to the use of these variables, first because air temperature and precipitation records are the most common and, second, it is easy to measure variables by means of both the large network of automatic weather stations as well as the historical meteorological database. Many locations worldwide - above all in Europe - have maintained temperature and precipitation records for decades, in some cases even centuries.

The aim of this paper is to propose a definition and index to describe and quantify meteorological diversity. A meteodiversity index takes into account the main recorded variables (observed and measured) as well as the phenomena and events that occur in a location. Furthermore, it should be able to quantify the diversity of weather in the same way that a biodiversity index estimates complexity in an ecosystem.

The structure of the article is as follows. The next section focuses on the definition of the term meteodiversity, and we discuss the benefits that it could provide for meteorology and climatology. In the following section, we propose the meteodiversity index, which allows us to quantify meteorological diversity. We then move on to evaluate its application in three different European climatic regions: Llanfairpwllgwyngyll (UK), Barcelona (Spain) and Helsinki (Finland). We end with a discussion surrounding our conclusions.

\section{The concept of meteodiversity}

We define meteodiversity as the variety of different types of meteorological phenomena in a defined area. Meteodiversity takes into account the proportion of one individual meteorological phenomenon (similar to Shannon's 'individuals', but within the meteorological context) belonging to the whole cluster of meteorological phenomena in the region ('the species') in the dataset of interest.

Some of the benefits of the adoption of this new conceptual framework are as follows:

(a) It allows classification of the diversity of weather over a period by considering not only temperature and precipitation, but also by integrating the maximum number of meteorological observations, phenomena and events. Currently, climatologists and meteorologists commonly use only temperature and precipitation to differentiate between warm (cold) and dry (wet) weather. Considering meteodiversity enriches the classification because it integrates many atmospheric variables instead of only one or two for classifying the weather.

(b) It provides the scientific community with a new perspective for the evaluation of a region's weather and climate. 
(c) It will allow analysis of the evolution of weather diversity over recent decades and thus evaluation of how climate change is altering the meteorological diversity.

(d) By including a large number of meteorological features, it will contribute to an improved classification of meteorological diversity over decades, years, months and days. It will facilitate analysis of the frequency, variety and sensitivity of the absolute numbers of meteorological observations, specifically in relation to meteorological diversity. In other words, climatologists can establish which climates are more diverse and by how much.

\section{The meteodiversity index}

Inspired by the index suggested by Shannon (1948), we define the meteodiversity index (MI) as:

$$
M I=-\sum_{i=1}^{S} p_{i} \ln p_{i}
$$

where $S$ is the total number of different recorded or observed weather phenomena occurring in a location, and $p_{i}$ is the proportion of the number of cases of the meteorological phenomena $i\left(n_{i}\right)$ with respect to the total number of occurrences of a particular phenomenon and events $(N)$. In other words, $p_{i}=n_{i} / N$.

This meteorological index takes into account both the number of different meteorological phenomena, events and weather observations occurring over the area under study and the relative quantity of each type in the database of interest.

One of the key tasks for optimal estimation of meteodiversity is to define a dataset of interest, which should include a large number of instrumental and observed meteorological data with additional information that has been extracted from the data. Some of these additional data, such as the number of warm or cold days or nights, are defined in the glossary of the World Meteorological Organization. Some others can be calculated from the instrumental or observed records and then be included due to their important contribution to diverse weather. Some examples are as follows: the number of days with precipitation higher than, for instance, 0.1, 10 or $20 \mathrm{~mm}$; the number of foggy days; thunderstorms; hail events; freezing conditions; tornadoes; fog; and the number of sunshine hours per year/month/week, among many others.

It is important to include a large number of atmospheric observations and measurements when populating the database used to estimate Ml to try to avoid a change of the variables that produces no variation in could decrease while the number of dry days increases in exact proportion, such that MI does not change. In these cases, it should be concluded that meteorological diversity does not change, despite variation in some atmospheric patterns. A database containing large numbers of observations and measurements reduces the occurrence of these situations.

\section{Application}

In this section we evaluate MI at monthly and annual temporal scales by using two databases that contain different information.

By using data from the Met Office, MI has been evaluated at a monthly resolution for Llanfairpwllgwyngyll (UK). This location has a Cfb (oceanic) climate, according to the Köppen climate classification (Peel et al., 2007). The dataset of interest used in this case includes the following variables provided by the Met Office (index s in Equation 2 runs from 1 to 10), which are the number of days with: grass frost; air frost; hail; precipitation greater than or equal to $0.2 \mathrm{~mm}$, precipitation greater than $1 \mathrm{~mm}$ and precipitation greater than $10 \mathrm{~mm}$; snow falling; sleet/snow falling; snow lying; and thunderstorms; as well as the number of sunshine hours. Figure 1 shows the average monthly values of $\mathrm{MI}$ at Llanfairpwllgwyngyll for the period 1981-2010. As can be observed, January and December (winter time) show the greatest diversity in weather, whereas June and July (summer time) show the lowest diversity. In average terms, the meteorological diversity at this station may be quantified with $\mathrm{MI}=1.2$.
By using yearly averaged data from the European Climate Assessment and Dataset (ECA\&D), $\mathrm{Ml}$ is evaluated for the period 1980-2014 at Helsinki (Dfa climate, humid continental) and Barcelona (Csa climate, Mediterranean).

The dataset of interest (index $S$ runs from 1 to 8 here) that was built and is used here (from ECA\&D) contains the number of frosty days, icy days, snowy days, rainy days, heavy rain days, very heavy rain days, summer days, and tropical nights (see the ECA\&D glossary for the corresponding definitions). Figure 2 shows the estimated value of $\mathrm{MI}$ every year from 1980 to 2014 at both locations. A weak increase in the trend of $\mathrm{Ml}$ is evident over Helsinki (0.0015 year $\left.{ }^{-1}\right)$, whereas this trend is larger over Barcelona $\left(0.0032\right.$ year $\left.^{-1}\right)$. Moreover, large variability in the value of $\mathrm{Ml}$ is observed since 1998 over Barcelona (interannual values), whereas MI remains more stable in Helsinki.

\section{Discussion and conclusions}

We have explored the diversity of meteorological phenomena occurring in three locations using the concept of meteodiversity. Based on the classical mathematical index of Shannon, an index for quantifying this diversity is additionally proposed and applied, by way of example, over three randomly chosen locations (but each in a specific climatological zone), all of which have different records in the database used and were evaluated at different temporal scales.

The data from the Met Office were used to evaluate MI monthly for the period 19812014. Wintertime (December, January and

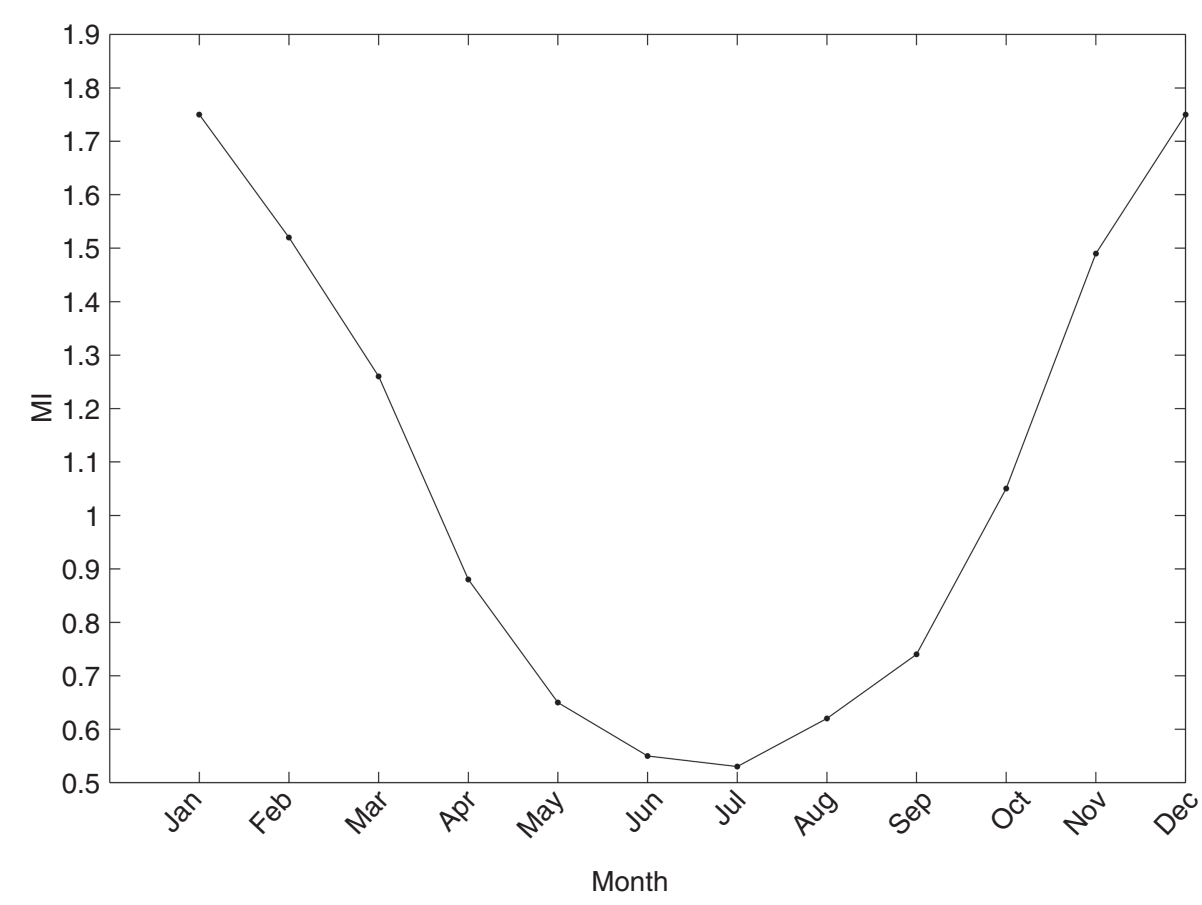

Figure 1. Averaged monthly Meteorological Index (MI) over the months during the period 1981-2010 at Llanfairpwllgwyngyll (53 $\left.3^{\circ} 13^{\prime} 15.6^{\prime \prime} \mathrm{N}, 4^{\circ} 12^{\prime} 21.6^{\prime \prime} \mathrm{W}\right)$. 


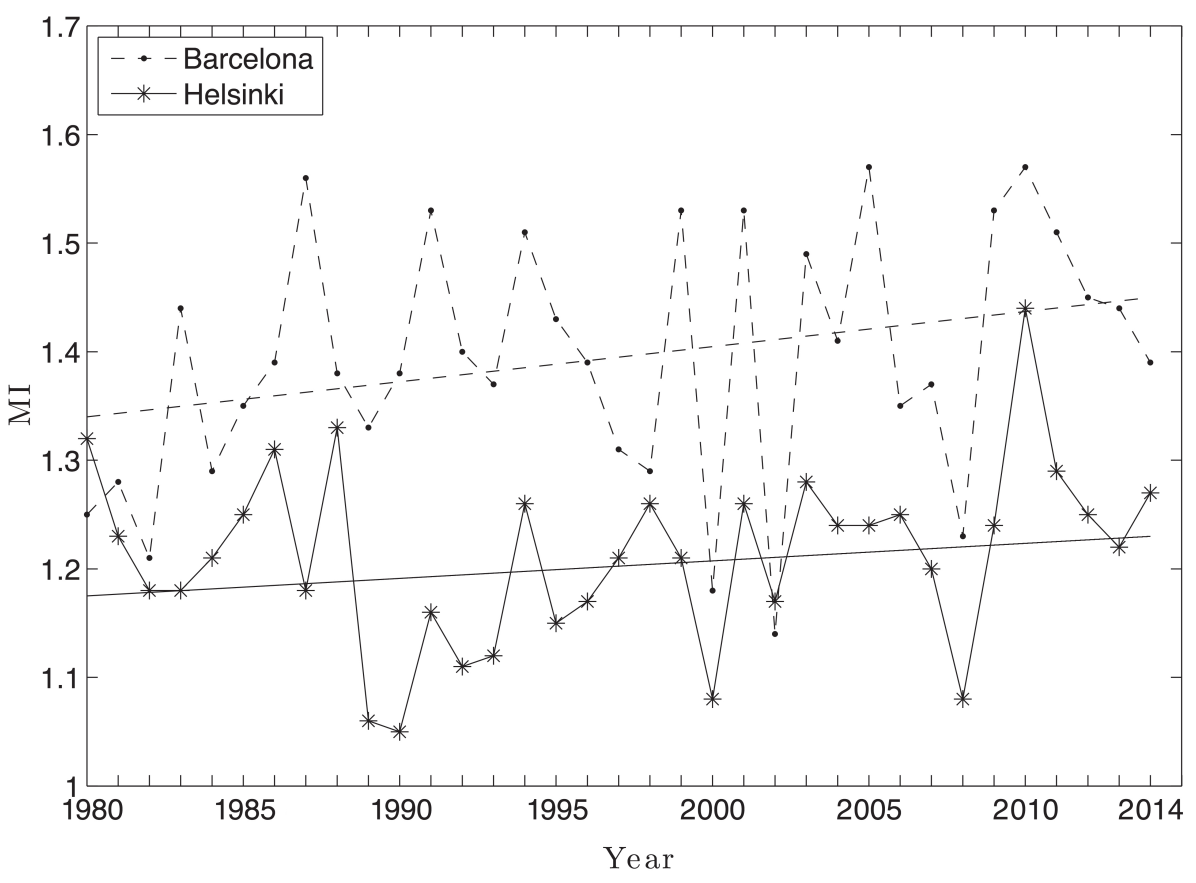

Figure 2. Meteorological Index (MI) evaluated on an annual scale for the period 1980-2014 at Barcelona (dot-dashed line) and Helsinki (asterisk/solid line). Trends are indicated by the solid (Helsinki) and dashed (Barcelona) straight lines.

February) shows higher MI values, with an average of 1.7, while summertime (June, July, August) shows lower values, with an average of 0.6. By using annual data from ECA\&D from 1980 to 2014 at Barcelona and Helsinki, the MI indicates larger interannual variability during the period 19982014. MI during this period also shows a stronger positive trend at Barcelona than at Helsinki.

It is important to note the relevance of the type and number of data included in the database used to evaluate the MI. The observational data include items such as the number of days of fog, number of warm or cold days or nights, freezing days, hail, sleet/snow falling, snow lying and thunderstorms, among many others. These play an essential role in describing the diversity of weather and, consequently, in quantifying MI.

This index obviously depends on the number and type of atmospheric variables included in the database of interest used. For this reason, it is fundamental that a unified database is available that contains the same atmospheric variables so that the MI can be compared for different places. The various national meteorological services currently have no consensus about the type of variables used to describe climate, and deciding which basic variables to include in the database for estimating MI would be a complex task. However, this challenge could (or a season, a year or a specified period) that defines how diverse the weather has been, and they may even estimate the values over a region, country or continent. This information will be richer than when evaluating only one variable, such as precipitation (to classify between rainy and dry) or temperature (to classify between warm and cold). Finally, climatologists may evaluate trends in weather diversity over years in order to advance knowledge of the climate system and to improve climate change analysis.

\section{Acknowledgments}

The authors acknowledge the data provided by the ECA\&D (http://www.ecad.eu) and the Met Office, as well the constructive comments and suggestions provided by the two anonymous reviewers and the editor.

\section{References}

Fraedrich K, Gerstengarbe FW, Werner PC. 2001. Climate shifts during the last century. Clim. Change 50: 405-417.

Gonzalez P. 2001. Desertification and a shift of forest species in the West African Sahel. Clim. Res. 17: 217-228.

Grieser J, Kottek M, Beck C et al. 2006 World map of Köppen-Geiger climate classification updated. Meteorol. Z. 15(3): 259-263.

Guetter PJ, Kutzbach JE. 1990. A modified Koeppen classification applied to mode simulations of glacial and interglacial climates. Clim. Change 16: 193-215.

Kalvova J, Halenka T, Bezpalcova K et al. 2003. Köppen climate types in observed and simulated climates. Stud. Geophys.

Geod. 47: 185-202.

Köppen W, Geiger R. 1936. Das

geographische system der Klimate, in Handbuch der Klimatologie, Band. 1, Teil C C 42-43. Berlin: Gebrüder Bornträger 1936.

Lohmann U, Sausen R, Bengtsson L et al. 1993. The Köppen climate classification as a diagnostic tool for general circulation models. Clim. Res. 3: 177-193.

Peel MC, Finlayson BL, McMahon TA. 2007. Updated world map of the KöppenGeiger climate classification. Hydrol. Earth Syst. Sci. 11: 1633-1644.

Pino D, Ruiz-Bellet JL, Balasch JC et al. 2016. Meteorological and hydrological analysis of major floods in NE Iberian Peninsula. J. Hydrol. 541: 63-89.

Triantafyllou GN, Tsonis AA. 1994.

Assessing the ability of the Köppen system to delineate the general world patterns of climates. Geophys. Res. Lett. 21: 2809-2812.

Shannon CE. 1948. A mathematical theory of communication. Bell Syst. Tech. $J \mathbf{2 7}$ : 379-423.

Wang M, Overland JE. 2004. Detecting arctic climate change using Köppen climate classification. Clim. Change $\mathbf{6 7}$ 43-62.
Correspondence to: Jordi Mazon Bueso jordi.mazon@upc.edu (c) 2017 Royal Meteorological Society doi:10.1002/wea.2945 